\title{
AS COMPETIÇÕES INFANTOJUVENIS À LUZ DA PEDAGOGIA DO ESPORTE
}

DOI: $105902 / 0102830820529$

Data de submissão: 25-11-2015

Data de Aceite: 11-02-2016

\author{
Hannah Aires \\ Universidade Federal do Rio Grande Sul \\ aireshannah@hotmail.com \\ Gabriel Henrique Tremer Gonçalves \\ Universidade Federal do Rio Grande \\ Sulghtg@hotmail.com \\ Roberto Tierling Klering \\ Universidade Federal do Rio Grande \\ Sulrobertoklering@hotmail.com \\ Carlos Adelar Abaixe Balbinotti \\ Universidade Federal do Rio Grande \\ Sulcarlos.balbinotti@ufrgs.br
}

Resumo: O presente artigo de revisão objetiva estabelecer quais categorias são essenciais à um modelo de competição esportiva infantojuvenil. A coleta de dados foi realizada em quatro fases: 1) Identificação das fontes; 2) Compilação; 3) Fichamento; e 4) Análise e interpretação. Os resultados apontam para duas categorias pilares do modelo competitivo infantojuvenil: a) A competição enquanto elemento estruturante da formação integral do indivíduo e b) A competição de acordo com as possibilidades e expectativas do público infantojuvenil. Verificada a carência de estudos na área, espera-se que esta pesquisa fomente o desenvolvimento de estudos empíricos para identificar necessidades específicas de cada modalidade.

Palavras-chave: Criança. Adolescente. Esportes. Educação. 


\section{Introdução}

A história do esporte e da competição esportiva se confundem e, em meio a um emaranhado de conceitos, se entrelaçam, sendo fundamental a concepção de um para a existência do outro (BARBANTI, 2006). Neste mesmo sentido, Marques (2004) afirma novamente que não há esporte sem competição e, portanto, separar os dois tornaria o primeiro uma prática sem sentido. A competição infantojuvenil institucionalizada é um fenômeno relativamente recente e que tem ganhado força rapidamente (THOMSON, 1996). Contudo, a participação em atividades esportivas e competições na infância, ou em diferentes fases da vida, apenas se dará graças a oportunidades e propostas que promovam o interesse de seu público-alvo. A partir da elaboração de propostas adequadas com as necessidades e expectativas do público-alvo, espera-se que o contingente de interessados seja maior, no entanto, as propostas devem apresentar especial cuidado com os aspectos pedagógicos dessas práticas.

Bento (2006) define que "[...] o desporto exibe um estatuto moral e cultural precisamente por ser um jogo de confronto, ou competição. Em que as pessoas se opõem umas as outras, para medir forças [...]". Aliado a isso, está o Agon - citado por Monteiro, Moraes e Carmona (2014) como o principal agente pedagógico do esporte. Ressaltam que "mais do que a luta pela conquista de um resultado, aquilo que chamamos de espírito agônico tratase de um combate que o homem trava consigo mesmo para superar os seus limites e a sua condição", criando assim uma oportunidade para a aquisição de novos conhecimentos; seja sobre o esporte, seja sobre o próprio ser, seja para a vida.

São encontrados na literatura diversos estudos (ROST, 1997, MARTIN et al, 2004, MESQUITA, 2000, MARQUES, 2004, DE ROSE JÚNIOR, 2004, ARENA; BOHME, 2004, TORRES; HAGER, 2007, MILISTETD et al, 2008, MALINA, 2009, CAZETTO, 2010, HIRAMA, MONTAGNER, 2009, CONDE et al, 2010, SHIELDS; BREDEMEIER, 2011, SHIELDS; FUNK, 2011, FENOGLIO; TAYLOR, 2012, GONÇALVES, 2014) que investigam a competição infantojuvenil no intuito de colaborar para sua melhor adequação às necessidades, capacidades e interesses das crianças e adolescentes, reforçando assim suas propriedades pedagógicas. Cabe ressaltar que os autores citados acima não estabelecem 
diferenciações no ensino da competição para esportes individuais ou coletivos. Portanto, na busca de uma teoria da competição para jovens esportistas, Marques (2004) define que o esporte para crianças e adolescentes deve ser pensado a fim de estabelecer uma relação de continuidade e complementaridade entre treino e competição. Entre os fatores que buscam ser contemplados nas propostas que defendem a competição para crianças e adolescentes podem-se citar: objetivos ou finalidades mais globais, que colaborem com a educação integral dos praticantes; métodos mais ativos que envolvam os jovens com mais intensidade em relação aos aspectos motores e cognitivos; inclusão dos valores educativos nos conteúdos trabalhados; e introduzir uma competição que se adapte às necessidades reais das crianças que iniciam a prática esportiva (CONDE et al, 2010).

No entanto, é sabido que as competições infantojuvenis podem apresentar problemas (KOHN, 1992, MARQUES, 2004, COAKLEY; DONNELLY, 2009, COSTA; KUNZ, 2012). Considerar crianças como adultos em miniatura, não considerar as potencialidades pedagógicas dos resultados competitivos e fazer com que as crianças pratiquem o esporte para entreter adultos são alguns exemplos. Esses problemas são considerados como oriundos de uma inadequada estruturação das competições esportivas infantojuvenis; encontrados ainda em determinadas modalidades esportivas, sejam individuais ou coletivas, que podem tornar os efeitos resultantes da participação competitiva antagônicos àqueles desejados. Com isso, a competição esportiva pode ser vista de maneira equivocada, relacionada a um contexto de guerra (SHIELDS; FUNK, 2011). Ver a competição dessa forma vai de encontro ao real significado da palavra "competição", que representa a criação de uma relação de ajuda mútua na busca pela excelência no desempenho (HYLAND, 1988).

A partir deste panorama, este estudo busca realizar uma ampla revisão de literatura sobre a competição esportiva infantojuvenil. Mais especificamente, sobre as principais características necessárias a um modelo de competição esportiva para crianças e adolescentes que possa ser utilizado como um instrumento pedagógico. 


\section{Método}

De acordo com Thomas, Nelson e Silvermann (2012), os estudos de revisão de literatura tem como objetivo buscar publicações que possam ser relacionadas umas com as outras com base em suas semelhanças e assim produzir uma compilação dos conhecimentos de determinada área de acordo com as delimitações do estudo. Para este estudo foram escolhidas como palavras-chave: competição esportiva, competição infantil e pedagogia. Com o estabelecimento das palavras-chave, procedeu-se com a busca de textos que contivessem pelo menos um dos termos escolhidos e a partir da localização do texto foi realizada sua leitura para optar pela inclusão ou não no estudo. Para ser incluído, o texto deveria ir ao encontro do objetivo traçado para o estudo. Assim, este estudo de revisão de literatura foi realizado conforme as seguintes etapas: 1)Identificação das fontes, 2) Compilação, 3) Fichamento e 4) Análise e interpretação.

Realizado o processo de análise e interpretação dos dados encontrados, foi possível classificar as características essenciais à construção de um modelo competitivo esportivo infantojuvenil em quatro categorias. A seguir, estão descritas as categorias identificadas e suas principais características.

\section{As funções da competição}

O poder socializador e agregador de valores éticos e morais da prática esportiva é indiscutível, isso se deve ao fato de que o esporte contém valores inerentes de autodescobrimento, desenvolvimento pessoal e educação social como o companheirismo, o espírito de luta e o respeito pelos demais e as normas (TREPAT DE FRANCISCO, 1999). A competição, por sua vez, não é um fator exclusivo das experiências esportivas, estando presente também em outros setores da vida, nos quais o ser humano compete em todos em que atua: família, escola, trabalho e sociedade (DE ROSE JÚNIOR, 2004). Através dessa afirmação do autor é possível perceber que a competição não é algo estranho e que deva ser evitado para as crianças uma vez que ela se faz presente no seu universo atuante. $\mathrm{Na}$ grande maioria das disciplinas esportivas a competição é parte indissociável do treinamento de crianças e adolescentes. A diferenciação existente entre o esporte realizado nas aulas 
de educação física e o esporte de alto rendimento, não é explicitada nos textos, é feita a referência ao esporte como um todo. Devido a esse fato, muitas vezes os termos professor e treinador, são utilizados com o mesmo significado e a palavra treinamento, por sua vez, aparece nos textos como o momento em que há o aprendizado da técnica esportiva.

Martin et al. (2004) apontam que a ampliação dos programas de competição para crianças e jovens é pouco apoiada por metodologias alternativas e adequada aos mesmos na maioria das disciplinas esportivas. Este autor estabelece funções que as competições devem contemplar para o contexto infantil e juvenil. Entre as funções propostas podemos destacar a função formativa e a educativa. Na formativa as competições têm como objetivo primordial a resolução das tarefas e não o rendimento em tarefas específicas, como ocorre no modelo adulto, ou seja, funcionam como incrementos na aprendizagem. Já a função educativa das competições se dá durante o transcurso das mesmas, pois nelas ocorrem situações nas quais o caráter do individuo é posto à prova. Fato este que faz das competições um momento ideal para o correto desenvolvimento e avaliação de aspectos relacionados à conduta dos esportistas infantojuvenis. Em seguimento Harre (1987) propõe outra função para competição que também merece destaque, a função social. Para este autor, os competidores devem, além de buscar o desenvolvimento físico, buscar o desenvolvimento moral, atuando de maneira harmoniosa com a sociedade, servindo de modelo para os demais.

\section{O papel do treinador}

Além das funções que a competição deve exercer no contexto infantojuvenil, é importante considerar as implicações que o exercício da atividade competitiva tem sobre seus participantes. Luta, antagonismo, vencer, perder, comparar rendimentos, prazer, pressão e tensão são fatores advindos de uma competição. O equilíbrio entre esses fatores é o grande desafio para os atletas e principalmente para os treinadores (DE ROSE JÚNIOR, 2004). O treinador é o principal responsável pela iniciação, orientação e especialização dos praticantes e a qualidade de sua intervenção contribui decisivamente para a existência de uma correta atitude formativo-educativa no contexto esportivo (MESQUITA, 2000). As situações que o treinador e o atleta compartilham podem ser as mesmas compartilhadas 
em atividades não esportivas. O que as torna diferentes são os valores intrínsecos das práticas motoras. Entre eles, é possível ressaltar o valor agonístico, que é o responsável por conferir a intencionalidade competitiva, a luta contra algo, alguém ou si próprio (VARGAS, 1999) - nem sempre em um sentido negativo. Nesse ponto de vista é importante considerar quais seriam os princípios orientadores da ação dos técnicos que, como mencionado anteriormente, são os responsáveis pela formação dos praticantes tanto nos treinamentos como principalmente durante as competições. Mesquita (2000) apresenta os seguintes princípios como norteadores:

1) Os treinadores devem ser apologistas de ações corretas (senso de justiça, imparcialidade, compreensão, serenidade, tolerância, paciência);

2) Os treinadores devem fazer com que os objetivos de formação (desenvolvimento de comportamentos corretos, válidos e conscientes) do treino e da competição durante a carreira esportiva se sobreponham aos objetivos de rendimento;

3) O objetivo de participar em competições, além da obtenção de resultados, deve ser contribuir para afirmação pessoal, autoafirmação e autossuperação;

4) Os praticantes só devem participar de competições a partir do momento em que possuam habilidade para responder aos problemas que emergem das mesmas.

Nessa perspectiva, Paccagnella (2003) acrescenta algumas sugestões de como os treinadores devem tratar a derrota com seus atletas:

1) Deve-se aprender lições a partir dos erros cometidos nas competições;

2) Manter o foco nos motivos e objetivos que levaram o atleta a competir;

3) Enfatizar com o atleta que se ele se esforçou para tentar alcançar o objetivo, ninguém poderá afirmar que ele não é um competidor de sucesso;

4) Elaborar um mecanismo para lidar com situações menos agradáveis para que o treinador e o atleta saibam como reagir e comportar-se nesses momentos;

5) Conhecer bem os praticantes e saber como eles gostam de ser tratados após o insucesso;

6) Procurar garantir que os praticantes continuem determinados, mesmo após uma situação desagradável. 
A competição como elemento estrutural da formação integral do indivíduo

Marques (2004) menciona que o esporte e a competição são apenas instrumentos para a educação e formação das crianças e jovens, os princípios e os valores associados à competição e a forma como esta é utilizada nas experiências vividas são o que confere o valor educativo. O componente educativo do esporte não reside na aprendizagem da técnica e tática e sequer nos benefícios físicos que sua prática traz, mas sim que as condições em que a prática é realizada permitam ao desportista comprometer-se e mobilizar suas capacidades de tal maneira que essa experiência proporcione configurar seu próprio eu e desenvolver sua auto-estruturação (VARGAS, 1999). Ayas (1999) complementa mencionando que a educação tem como principal objetivo a formação integral da personalidade, fazendo assim que os demais objetivos estejam subordinados a esse. Em consequência disso, um esporte somente será educativo quando as situações presentes nele permitirem o desenvolvimento das habilidades motrizes e psicomotrizes em relação aos aspectos afetivos, cognitivos e sociais da personalidade do praticante (VARGAS, 1999).

De forma geral, crianças e adolescentes são inseridos em programas esportivos com o objetivo de aprender mais sobre determinadas modalidades, mas principalmente para vivenciar e se apropriar dos valores do esporte educacional. Rossetto, Ardigó Junior e Costa (2009) resumem de forma bastante objetiva os principais objetivos do esporte educacional, muitos dos quais são citados anteriormente por outros autores: o resgate de valores humanos, como amizade, solidariedade e respeito; a integração do aluno com o ambiente de prática; a construção de regras, normas e atitudes positivas; a ampliação do desenvolvimento psicomotor, cognitivo e sócio-afetivo e a formação de cidadãos críticos, participativos e cientes de seu papel na sociedade.

O equilíbrio dos componentes motores, perceptivos, intelectuais, emocionais e psicológicos do indivíduo resulta na prontidão competitiva e a relação entre os componentes da mesma não ocorre em uma sequência linear e hermética (DE ROSE JÚNIOR, 2004). De Rose Júnior (2004) apresenta ainda que mesmo quando as capacidades individuais se encontram em patamares mais baixos que a demanda da tarefa, as crianças continuarão com a possibilidade de ter sucesso na competição. Isso ocorre devido a fatores como a 
motivação e os níveis de aspiração do praticante que influenciarão positivamente no resultado competitivo. Por isso, para assegurar experiências ricas e que proporcionem a formação integral do indivíduo, a motivação e também a competência nas habilidades realizadas pelas crianças durante as competições é que emerge a necessidade do conhecimento e compreensão de propostas competitivas mais conforme as crianças e adolescentes e suas fases de desenvolvimento físico, motor e psicossocial.

\section{A competição de acordo com as possibilidades e expectativas do público infantojuvenil}

Como a maioria dos sistemas competitivos ainda reproduz o modelo mais avançado, os sujeitos que se apresentam em elevados níveis de maturação biológica, aproximandose mais das capacidades de um individuo adulto, são os que alcançam os melhores resultados. Como consequência disso, já durante as etapas de formação esportiva, um grande contingente de praticantes que não se enquadra nesses fatores acaba deixando a prática por quebra de interesse e desmotivação (ROST, 1997, COSTA). Para evitar a ocorrência de situações como essa, Marques e Oliveira (2002) indicam a participação em competições organizadas oficialmente a partir dos 11 ou 12 anos ou mais tarde. Estes autores afirmam que apenas a partir dessas idades e após é que as crianças conseguiriam interagir com as exigências das competições como a compreensão das relações sociais, a análise das técnicas e habilidades dos adversários e experimentar o sucesso e o insucesso. Em seguimento a esse argumento, Rost (1997) ressalta que as competições esportivas oficiais não devem ser apresentadas para as crianças até o momento em que elas possuam capacidade para lidar de forma adequada com a derrota, antes disso para demonstrar suas habilidades elas devem participar de competições não oficiais, como os festivais (ARENA; BÖHME, 2004).

Situações como essa ocorrem devido ao fato de que o sistema de treino é desenvolvido em um nível crescente de especialização e a competição, ao invés de imitá-lo, faz o processo inverso e é realizada de acordo com o modelo de alto rendimento desde a fase inicial em muitas modalidades (MARQUES; OLIVEIRA, 2002). A importância da adequação das 
competições reside em elaborar uma articulação estreita entre o conteúdo das competições e os conteúdos do treino, de maneira que sejam considerados primordiais nessa construção os objetivos formativos (MARQUES, 1997). Rost (1997) menciona que, se organizadas de acordo com o modelo de alto rendimento, as cargas psicofísicas das competições são muito elevadas para as crianças e para os jovens levando muitas vezes a fenômenos de saturação psicológica. Para diminuir os aspectos negativos advindos da realização de competições inadequadas às capacidades e possibilidades das crianças e jovens, Rost (1997) e Marques (2004) propõem a implantação de conteúdos e estruturas no sistema de competições que priorizem oferecer apoio ao treinamento que esteja à medida da criança e do jovem, opor-se a especialização precoce e promover a construção de uma perspectiva em longo prazo da prestação esportiva nessas idades.

As modificações necessárias nas competições se justificam pela necessidade de criar situações de facilitação que permitam aos indivíduos a participação em atividades competitivas ao nível de suas qualidades e capacidades condicionadas pelos estágios de desenvolvimento, pela idade e pelo nível de treino (MARQUES, 1997). Na mesma perspectiva, Rost (1997) apresenta a necessidade da existência de uma sintonia entre o sistema de competição e cada etapa da preparação em longo prazo das crianças e jovens e indica que nos anos iniciais o resultado competitivo não deve ser encarado de forma clássica, mas que também devem ser considerados o progresso e a aproximação ao nível mais alto da modalidade. Assim, a modificação da competição em função dos objetivos de formação da prática esportiva pode levar seus efeitos até o próprio treino, fazendo que ele se adapte ao ritmo do desenvolvimento do praticante (ROST, 1997). Esse ponto é de suma importância, pois a consagração da harmonia entre os objetivos da formação e as expectativas que as crianças possuem em relação a sua participação em competições faz com que as mesmas atuem como elemento estruturante do treino (MARQUES, 2004).

Nos primeiros anos de treinamento as competições devem promover e respeitar os pressupostos de coordenação, técnico-táticos e orgânicos de acordo com a fase de desenvolvimento em que se encontram os sujeitos (ROST, 1997). Em sequência disso, Martin et al. (2004) menciona que através das competições do período inicial do treinamento devem ser desenvolvidas e estimuladas as capacidades mais responsivas a cada fase do 
desenvolvimento do praticante. Assim, as exigências da competição servirão para auxiliar a promoção de programas de ação coerentes com o avanço na modalidade (ROST, 1997).

Além da correta definição das exigências da competição, a maneira como são realizadas, objetivando diminuir os efeitos das derrotas sobre as crianças e jovens, torna-se um fator relevante no contexto estudado. Martin et al. (2004) propõe a realização de provas combinadas com conteúdos de competição alternativos e tradicionais, sendo a variação mais importante o fato da competição ser realizada em equipes. Nessas competições, o importante não é o desempenho individual, mas sim a classificação da equipe, fator este que contribui para o envolvimento positivo com a competição, pois é proporcionado aos participantes a oportunidade de viver a competição e se divertir; desenvolver o interesse pela disciplina esportiva e adquirir motivação para o treinamento; conhecer e adquirir o comportamento competitivo em situações específicas e desenvolver o sentimento de equipe. O único inconveniente desse método de realização é que o rendimento individual não pode ser quantificado, por isso caberá ao treinador, após a competição, em conjunto com seus atletas realizar as observações pertinentes a cada um de forma a construir o desempenho futuro de seus alunos.

A frequência das competições para as crianças e jovens também deve ser observada quando se trata da adequação da prática competitiva aos mesmos. A participação em um número reduzido de competições por parte das crianças e jovens sempre foi atribuída a sua falta de preparação, no entanto, há outra perspectiva que fomenta as participações competitivas presentes desde as fases de iniciais do treinamento, o que revela perspectivas paradoxais (MARQUES, 2004). Esse autor propõe também o aumento da participação em competições, no entanto, não somente nas que estiverem de acordo com o modelo formal, mas também em pequenas competições realizadas entre os próprios companheiros de treino, de forma menos estruturada e mais simplificada. Essas competições devem cumprir com o objetivo de auxiliar na formação possibilitando a oportunidade de comparar suas habilidades e assegurar a motivação dos praticantes uma vez que o esporte em si não possui nenhum sentido se não há a competição sendo realizada concomitantemente. Ainda de acordo com Marques (2004), para as competições realizadas de modo simplificado não há nenhum problema em que sua frequência seja elevada, pois é justamente este o fator 
que irá evitar a supervalorização do evento competitivo, assim como a derrota, pois haverá outra possibilidade próxima de melhorar seu desempenho competitivo.

Para as crianças e jovens, ao contrário dos atletas adultos, não é indicada a existência de uma periodização anual de treinamento com a intenção de preparar um alto nível de rendimento para um momento especifico, contudo, o que deve ocorrer é a igual valorização de todas as competições, caracterizando o principio da atividade competitiva durante o ano inteiro (MARTIN et al., 2004). O mesmo autor aponta que devido a isso algumas medidas devem ser tomadas pelos treinadores de modo a coordenar metodologicamente os objetivos e as tarefas para que ambos sejam satisfeitos de maneira ideal: 1) O acordo em conjunto com os desportistas sobre os objetivos e as principais tarefas do treinamento e das competições no princípio do treinamento anual; 2) A ênfase, em médio prazo, da preparação para as competições mais importantes que são essenciais para a satisfação dos objetivos formativos do ano e 3) A avaliação dos resultados alcançados nas competições desde o ponto de vista dos avanços atingidos em relação à aprendizagem.

Marques (2004) menciona que o ponto primordial que deve ser considerado quando se trata da realização de competições infantis e juvenis é a não reprodução de modelos competitivos de alto nível com o intuito de assegurar respostas mais fidedignas ao desempenho final da modalidade. Para que as competições infatojuvenis estejam mais adequadas aos seus participantes é necessário que os conteúdos, os métodos, as ações fomentadas pelo treinador sejam pensados de forma a potencializar as aprendizagens advindas dos eventos competitivos (MARQUES, 1997, MARQUES, 2004, ROST, 1997, MESQUITA, 2000, MARQUES; OLIVEIRA, 2002, MARTIN et al., 2004).

Com a finalidade de explorar a organização das competições esportivas para crianças e jovens no Brasil, Milistetd et al. (2014) e Arena e Böhme (2004) analisaram documentos relativos às federações esportivas de diversos esportes e realizaram entrevistas com seus representantes. Milistetd et al. (2014) menciona que a elaboração de adequações estruturais e funcionais já revelam a preocupação com o melhor aproveitamento competitivo dos jovens atletas, buscando evitar a especialização precoce. Quanto à participação em competições Arena e Böhme (2004) encontraram como um dos resultados de seu estudo, que o objetivo da realização de competições para os mais jovens seria formar futuros expoentes em 
suas modalidades e massificar o esporte. Esses autores sugerem a realização de festivais como meio de atingir esse objetivo, pois permitem a inclusão de um maior contingente de participantes e não são realizados de acordo com o modelo formal de competição.

Estes são estudos pioneiros no Brasil e possuem extrema relevância para o tema em discussão. Neste sentido, estão sendo realizadas pesquisas com o intuito de aprofundar o conhecimento das competições esportivas específicas de cada esporte, trazendo contribuições daqueles que estão de fato na prática - os treinadores. Dessa forma, pretendese auxiliar as instituições responsáveis pelas competições infatojuvenis a adaptar seus modelos de competição tornando-os mais conformes a esse público. O projeto guardachuva intitulado "Modelos de competições esportivas para crianças e jovens: um estudo descritivo-exploratório" possui este objetivo e já rendeu uma dissertação de mestrado relacionada ao tênis (GONÇALVES, 2014).

\section{Considerações finais}

Este estudo buscou, por meio de uma revisão bibliográfica, apresentar as características mais destacadas como necessárias a um modelo de competição para crianças e adolescentes. Durante a análise do conteúdo, foi possível estabelecer quatro categorias teóricas predominantes neste processo: a) as funções da competição; b) o papel do treinador; c) a competição como elemento estrutural da formação integral do indivíduo; e d) a competição de acordo com as possibilidades e expectativas do público infantojuvenil.

A partir da estruturação das categorias pode-se perceber que os textos analisados indicam que a competição esportiva pode ser um elemento essencial na formação integral do esportista infantojuvenil. Esse fato se justifica por diversos motivos, como o estímulo de valores positivos e pelo grande potencial pedagógico das experiências de vitória e derrota. Durante o transcurso das competições, além das vitórias e derrotas, outras situações que colocam à prova o caráter dos participantes também ocorrem, fazendo com que dilemas morais emerjam e sejam solucionados no momento. Por mais que as escolhas de cada esportista sejam individuais, devido ao período de formação pelo qual passa o público infantojuvenil, o treinador e suas atitudes são fundamentais na construção do caráter dos 
praticantes.

A conscientização da função que o treinador exerce nas fases iniciais da prática esportiva é o ponto de partida para se estabelecer um modelo competitivo tendo crianças e adolescentes como sujeitos principais do processo. O treinador apresenta-se como um dos personagens mais importantes da vida de muitas crianças e jovens, devido ao tempo de convivência e a dedicação que muitos jovens tem com a prática esportiva. Para atuar diretamente na formação integral de seus atletas é necessário que seu trabalho seja orientado por princípios baseados na realização de ações corretas e justas, promovendo valores como a autossuperação.

A compreensão das funções das competições e a conscientização da importância da reflexão acerca do papel do treinador na formação dos esportistas são entendidas como a base para a atuação das competições na formação e educação de seus participantes. Entretanto, para que as competições de fato atuem nessa perspectiva, é necessário que haja a adequação das mesmas ao público-alvo e que sejam ambientes que promovam ações como as citadas anteriormente.

A competição adequada às possibilidades e expectativas das crianças e adolescentes é outra categoria evidenciada neste estudo. De forma geral, a bibliografia em questão sugere que a competição esportiva infantojuvenil não deve reproduzir o modelo adulto de altorendimento. Isto se deve por diversos motivos, como uma possível especialização precoce e a perda de motivação para a prática decorrente da incapacidade de realização dos desafios propostos. Neste sentido, tem se observado uma tendência de preocupação por parte de algumas federações esportivas com a criação de modelos competitivos pensados nas crianças e adolescentes - Tennis 10's, Mini Voleibol, Mini Handebol, etc.

É importante destacar que alguns estudos, com a finalidade de analisar as competições infantojuvenis, já foram realizados. Contudo, duas questões ainda são necessárias: o desenvolvimento de estudos empíricos ou experimentais e buscar identificar as necessidades específicas de cada modalidade. Ressalta-se, portanto, a possibilidade de novos estudos nestas perspectivas, a fim de fazer da competição infantojuvenil um instrumento mais forte a contribuir para a formação integral de crianças e adolescentes.

Foi possível perceber que esta temática ainda é uma questão muito pertinente e 
relevante. A quantidade de livros e capítulos teorizando o assunto demonstra isso. No entanto, ainda é pequeno o número de artigos originais sobre o tema, limitando uma discussão mais aprofundada sobre a real situação de quem está na prática. Por fim, cabe ressaltar que a formação integral do jovem esportista não cabe somente aos aspectos relacionados à competição esportiva unicamente. Contudo, julgou-se adequada a análise restrita às abordagens competitivas pela relevância que esta prática possui na constituição do esporte atual.

\section{Referências}

ARENA, S. S.; BÖHME, M. T. S. Federações esportivas e organização de competições para jovens. Revista Brasileira de Ciências e Movimento, Brasilia, v. 12, n. 4, p. 45-50, 2004.

AYAS, J. C. Características pedagógicas del deporte. In: BLÁZQUEZ-SÁNCHEZ, D. La iniciación deportiva y el deporte escolar. Barcelona: Inde, 1999. p. 49-60.

BARBANTI, V. O que é esporte? Revista Brasileira de Atividade Física \& Saúde, v. 11, n. 1, p. 54-58, 2006.

BENTO J. O. Desporto e lusofonia: um traço de união. Porto: Faculdade de Desporto da Universidade do Porto, 2006.

CAZETTO, F. F. Influências do esporte espetáculo sobre as lutas e as artes marciais: reflexões sobre a educação dos mais jovens. Lecturas Educación Física y Deportes, Buenos Aires, v. 148, p. 1-1, 2010.

COAKLEY, J.; DONNELLY, P. Sports and children: are organized programmes worth the effort? In: COAKLEY, J.; DONNELLY, P. Sports in society: issues and controversies. [s.I.]: Mcgraw-Hill, 2009. p. 113-146. 
CONDE, C. et al. La formación multideportiva de los jóvenes que se inician en el deporte. Wanceulen $\mathbf{E}$. F. Digital, Sevilla, n. 7. p. 51-58. dez. 2010.

COSTA, A. R.; KUNZ, E. Render e produzir no esporte: Rendimento obrigatório ou Rendimento necessário? Kinesis, Santa Maria, v. 30, n. 2, p. 45-54, jul./dez. 2012.

DE ROSE JÚNIOR, D. Tolerância ao treinamento e à competição: aspectos psicológicos. In: GAYA, A.; MARQUES, A.; TANI, G. Desporto para crianças e jovens: Razões e finalidades. Porto Alegre: UFRGS, 2004. p. 251-264.

FENOGLIO, R.; TAYLOR, W. From winning-at-all-costs to give us back our game: perspective transformation in youth sport coaches. Physical Education and Sport Pedagogy, v. 19, n. 2, p. 191-204, 2014.

GONÇALVES, G. H. T. A competição de tênis como modelo de educação e formação de crianças: o caso das categorias até 10 anos. 2014. 114 f. Dissertação (Mestrado em Ciências do Movimento Humano) - Escola de Educação Física, Universidade Federal do Rio Grande do Sul, Porto Alegre, 2014.

HARRE, D. Teoría del entrenamiento deportivo. Buenos Aires: Stadium, 1987.

HIRAMA, L. K.; MONTAGNER, P. C. A ação pedagógica da competição esportiva. Movimento e Percepção, v. 10, p. 109-121, 2009.

HYLAND, D. A. Competition and friendship. In: MORGAN, W. T.; MEIER, K. V. Philosophic inquiry in sport. Illinois: Human Kinetics, 1988.

KOHN, A. No Contest: the case against competition. Boston: Houghton Mifflin, 1992

MALINA, R. M. Children and adolescents in the sport culture: the overwhelming majority to the select few. Journal of Exercise Science and Fitness, v. 7, n. 2, p. S1-S10, 2009.

MARQUES, A. A preparação desportiva de crianças e jovens: o sistema de competições. In: GUEDES, 0. 
Atividade física: uma abordagem multidimensional. João Pessoa: Ideia, 1997. p. 157-169.

MARQUES, A. T. Fazer da Competição dos mais Jovens um Modelo de Formação e Educação. In:

GAYA, A.; MARQUES, A.; TANI, G. (Org.). Desporto para crianças e jovens: razões e finalidades. Porto Alegre: UFRGS, 2004. p. 75-96.

MARQUES, A.; OLIVEIRA, J. O treino e a competição dos mais jovens: rendimento versus saúde. In: BARBANTI, Valdir José. Esporte e atividade física: interação entre rendimento e qualidade de vida. São Paulo: Manole, 2002. p. 51-73.

MARTIN, D. et al. Metodología general del entrenamiento infantil y juvenil. Barcelona: Paidotribo, 2004.

MESQUITA, I. Pedagogia do treino: a formação em jogos desportivos coletivos. 2. ed. Lisboa: Livros Horizonte, 2000.

MILISTETD, M. et al. Análise da organização competitiva de crianças e jovens: adaptações estruturais e funcionais. Revista Brasileira de Ciências do Esporte, v. 36, n. 3, p. 671-678, 2014.

MILISTETD, M. et al. Concepções dos treinadores acerca do papel da competição na formação desportiva de jovens jogadores de voleibol. Revista da Educação Física/UEM, Maringá, v. 19, n. 2, p. 151-158, 2008.

MONTEIRO, A. O.; MORAES, J. C.; CARMONA, E. K. Paideia: a base cultural do desporto. Revista Brasileira de Ciência e Movimento, v. 22, n. 1, p. 175-180, 2014.

PACCAGNELLA, M. Como lidar com o insucesso e com o desapontamento: Estratégias para ajudar os praticantes (e os próprios treinadores). Revista Treino Desportivo, Lisboa, v. 5, n. 22, p. 46-47, 2003.

ROST, K. As Competições no Desporto Juvenil. Treino Desportivo, Lisboa, p. 3-10, jul. 1997. 
ROSSETTO, Adriano J.; ARDIGÓ JUNIOR, Ambleto; COSTA, Caio Martins. Jogos Educativos: Estrutura e Organização da Prática. 5. ed. São Paulo: Porte, 2009.

SHIELDS, D. L.; BREDEMEIER, B. L. Why sportsmanship programs fail, and what we can do about it. Journal of Physical Education Recreation and Dance, v. 82, n. 7, 2007.

SHIELDS, D. L.; FUNK, C. Teach to Compete. Strategies: a Journal for Physical and Sport Educators, v. 24, n. 5 p. 8-11, 2011.

THOMAS, J.; NELSON, J.; SILVERMAN, S. Métodos de pesquisa em atividade física. 6. ed. Porto Alegre: Artmed, 2012.

THOMSON, R. W. Youth sport involvement in New Zealand: issues, images and initiatives. FIEP Bulletin, v. 66, n. 1, p. 22-27, 1996.

TORRES, C. R.; HAGER, P. F. De-emphasizing competition in organized youth sport: misdirected reforms and misled children. Journal of the Philosophy of Sport, v. 37, n. 2, p. 292-309, 2007.

TREPAT DE FRANCISCO, D. La educación en valores a través de la iniciación deportiva. In: BLÁZQUEZ-SÁNCHEZ, D. La iniciación deportiva y el deporte escolar. Barcelona: Inde, 1999. p. 95-110.

VARGAS, F. S. Valores educativos del deporte. In: BLÁZQUEZ-SÁNCHEZ, D. La iniciación deportiva y el deporte escolar. Barcelona: Inde, 1999. p. 61-74. 


\section{JUNIOR COMPETITIONS BY SPORT PEDAGOGY POINT OF VIEW}

Abstract: This review paper aims to establish which categories are essential to elaborate a junior sports competitive model. The data collection was conducted in four steps: 1) Source identification; 2) Compilation; 3) Book/paper report; and 4) Analysis and interpretation. The results indicate two categories as pillars of the junior sports competitive model: a) Competition as a structuring element of the individual's integral formation; and b) Competition according to junior's possibilities and expectations. Verified the lack of studies in the area, it is expected that this research will promote the development of empirical studies to identify specific needs of each mode.

Keywords: Child. Adolescent. Sports. Education.

\section{LAS COMPETICIONES INFANTOJUVENILES BAJO LA LUZ DE LA PEDAGOGÍA DEL DEPORTE}

Resumen: El presente estudio de revisión bibliográfica objetiva establecer cuáles las categorias esenciales a un modelo de competición deportiva infantojuvenil. Los datos fueron coletados en cuatro fases: 1) Identificación de las fuentes; 2) Compilación; 3) Fichamento; y 4) Análisis e interpretación. Los resultados indican dos categorias esenciales: a) La competición como elemento estructurante de la formación integral del indivíduo y b) La competición a la medida de las posibilidades y expectativas del público infantojuvenil. Verificada la falta de estudios en el área, se espera que esta investigación fomente el desarrollo de estudios empíricos para identificar las necesidades específicas de cada modalidad.

Palabras-clave: Niño. Adolescente. Deportes. Educación. 